\title{
Prescription Drug Attitudes Questionnaire: Development and Validation
}

\author{
Jamie S. Bodenlos1, Andrew Malordy1, Marleah Noonan1, Aubreyanne Mayrsohn1, \\ Brian Mistler ${ }^{2}$ \\ ${ }^{1}$ Hobart and William Smith Colleges, Geneva, USA \\ ${ }^{2}$ Ringling College of Art and Design, Sarasota, USA \\ Email: bodenlos@hws.edu
}

Received 9 July 2014; revised 5 August 2014; accepted 1 September 2014

Copyright (C) 2014 by authors and Scientific Research Publishing Inc.

This work is licensed under the Creative Commons Attribution International License (CC BY).

http://creativecommons.org/licenses/by/4.0/

(c) (i) Open Access

\begin{abstract}
The purpose of this study was to develop and validate a scale measuring attitudes towards prescription drug use for nonmedical reasons. Participants $(N=310)$ were recruited from a small northeastern college and completed the Prescription Drugs Attitudes Questionnaire (PDAQ), the College Alcohol Problems Scale (CAPS-R) and answered questions about current substance use. Principal components analysis of the PDAQ yielded a two-factor structure accounting for $58.2 \%$ of the total variance in attitudes toward prescription drugs where the factors represented items concerning Recreational and Achievement-Oriented attitudes. The PDAQ had good internal consistency (.94) and convergent validity with a measure of alcohol problems $(r=.37)$, alcohol use $(r$ $=.44)$, and illicit drug use $(r=.36)$. The PDAQ is a reliable and valid scale that can be used by researchers and clinicians to understand and prevent prescription drug abuse among youth.
\end{abstract}

\section{Keywords}

Drugs, Attitudes, Prescriptions, Scale Development, Psychometrics

\section{Introduction}

The nonmedical use and abuse of prescription drugs has become a serious problem in the United States. In 2010, almost 7 million individuals were using prescription drugs for nonmedical purposes. The medications most commonly used were pain relievers, tranquilizers, stimulants and sedatives (National Institute on Drug Abuse, 2011). These rates are also high among adolescents and college students. Recent data suggest that one in four adolescents has misused or abused a prescription medication at least once in their lifetime. Common among these misused drugs are stimulants, which one in eight teens report misusing or abusing (Drugfree.org \& Foundation, 
2013). In a recent review of the literature, Weyandt and colleagues (2013) found that rates of misuse of prescription stimulants ranged from 5.3\% - 34\% among college students.

The increased use and abuse of prescription drugs is of great concern. Drug overdose death rates in the United States are at an all-time high and have more than tripled since 1990 (CDC, 2011). Rates of emergency department visits related to prescription stimulants more than doubled between 2005 and 2010 (Substance Abuse and Mental Health Services Administration, 2013). Misuse of prescription drugs is also associated with high rates of abuse of illicit drugs and alcohol (Jardin, Looby, \& Earleywine, 2011; Sepulveda et al., 2011). Among college students, misuse of prescription drugs has been linked to poor academic performance (McCabe, Teter, \& Boyd, 2005) and high risk behavior including risky driving behaviors (McCabe, Knight, Teter, \& Wechsler, 2005), polydrug use, and blackouts (McCabe \& Teter, 2007). College students who report feeling hopeless, sad, depressed, or suicidal are at a greater risk for prescription drug misuse compared to those who don't experience these emotions or thoughts (Zullig \& Divin, 2012).

There are many possible explanations for this exponential rise in prescription drug abuse. For instance, there are more prescription drugs available now than ever before. The amount of prescriptions written for stimulants has increased from 5 million to 45 million between 1991-2010 and during that same time, opioid prescriptions have increased from 75.5 million to 209.5 million (National Institute on Drug Abuse, 2011). Another possible reason for increased misuse could be that individuals are often overconfident in a drug's safety because of its pharmaceutical association. Individuals may assume that because physicians prescribe certain drugs (although not for their own use), they are safe to take under any circumstances (Arria, Caldeira, Vincent, O'Grady, \& Wish, 2008). Society is routinely bombarded with messages from pharmaceutical companies about the benefits of prescription drug use, which in some ways normalizes drug use (Biegler \& Vargas, 2013). In fact, over a quarter of teens believe that it is safer to misuse prescription drugs than it is to use illicit drugs (Drugfree.org \& Foundation, 2013). There are also other reasons for the surge in misuse of such drugs. For instance, the youth report motivations for the use of prescription drugs that include: getting high, enhancing academic performance, coping with anxiety or sleep problems, social facilitation, losing weight, and increasing energy (Dussault \& Weyandt, 2013; Gomes, Song, Godwin, \& Toriello 2011; Partridge, Bell, Lucke, \& Hall 2013). Many young adults are also unaware of the negative consequences, side effects, and potential harms caused by the misuse of prescribed drugs (Weyandt et al., 2009), which may prevent them from making informed decisions about drug use.

Health behavior theories such as the Theory of Planned Behavior suggest that there is an important link between an individual's attitude and their subsequent behavior. The theory posits that attitudes toward the behavior are a critical factor that affects intention to engage in (or refrain from) that behavior (Azjen, 1985). This theory implies that there might be a link between college students' attitudes towards prescription drug use and their actual use of prescription drugs. In fact, previous research with college students suggests that misusers of prescription psychiatric medication were more likely to endorse positive attitudes regarding medication seeking compared to non-users. There was also a positive correlation between positive medication-seeking beliefs (i.e., I believe it is okay to fake symptoms of ADHD in order to receive a prescription) and medication seeking behaviors (Stone \& Merlo, 2012).

An essential piece still missing in this area of literature is a valid and reliable tool to assess attitudes towards prescription drugs. Such a tool would help researchers and practitioners assess individuals' views on taking prescription drugs for nonmedical purposes, what might be contributing to their misuse, as well as identify individuals who may be at risk for future misuse of prescription medications. Therefore, the purpose of this paper is to describe the development and validation of a new scale for measuring attitudes towards prescription drugs.

\section{Method}

\subsection{Participants}

Participants were 310 (210 females, 100 males) college students recruited from a small Northeastern college. Students were aged $18-24(\mathrm{M}=19.67, \mathrm{SD}=1.252)$ and the racial/ethnic composition was $85.2 \%$ Caucasian, 4.8\% Asian, 3.9\% African American, 4.8\% Hispanic and 1.3\% other. All participants provided informed consent as approved by the Institutional Review Board.

\subsection{Procedure}

After approval from the Institutional Review Board was obtained, participants were recruited from various 
academic departments with flyers, online advertisements and class announcements. Participants had the option of being entered in a raffle for a gift card or earning course credit in exchange for participating in the study. Because of the possibility that many participants might not have been knowledgeable about different drug categories, we provided them with a list of commonly used prescription and illicit drugs. After providing informed consent, participants were instructed to read over the list carefully and to then sign the form stating that they had read and understood the different drug categories. Participants were then asked to complete a series of selfreport questionnaires. In order to control for order effects, the scales were counter-balanced.

\subsection{Measures}

Background Questionnaire Demographic data and lifestyle information were collected to assess participant age, ethnicity, class year, and gender. Participants were asked to report on their use of alcohol (drinks per week), marijuana (times per month), illicit drugs (times per month), and prescription pills (times per month) not prescribed to them by a doctor.

College Alcohol Problems Scale (CAPS-R) Problematic drinking behaviors were assessed using an 8-item scale asking participants to indicate how often problematic scenarios had happened to them over the course of the previous year as a result of alcohol consumption. For each given scenario, participants could respond using a 6-point Likert scale with 1 indicating that a scenario "never" occurred and 6 indicating that a scenario occurred " 10 or more times" in the past year. The two factors measured are personal and social problems that result from alcohol use. The CAPS has been previously used in college student populations and has been found to possess acceptable reliability and strong concurrent validity (O’Hare, 1998; O’Hare \& Sherrer, 1998; Talbott, Umstattd, Usdan, Martin, \& Geiger, 2009; West \& Graham, 2001). The CAPS has also been associated with alcohol abuse (West \& Graham, 2001).

Prescription Drug Attitudes Questionnaire (PDAQ) The Prescription Drug Attitudes Questionnaire was created to assess participants' attitudes and perceptions on various situations that involve the use of prescription medication for nonmedical use. Questionnaire items were generated by three researchers based on reviews of the literature and anecdotal information from interactions with college students who use prescription medications for nonmedical uses. After items were generated, all researchers reviewed the items and made appropriate edits (i.e., assessing the wording of items and removing redundant questions). The questionnaire was then pilot tested on 10 students and feedback on the items was generated and the scale was revised. Finally, items were reviewed by an expert in the field and further modified.

On the final set of 26 items, participants were asked to indicate the extent to which they agreed with each item using a 6-point Likert scale, with 0 indicating "strongly disagree" and 6 indicating "strongly agree." An example item reads "An individual should only take medication that is prescribed to them by a medical professional." To control for acquiescence, items were both positively and negatively worded. Higher scores indicated more positive attitudes towards prescription drug use for nonmedical reasons.

\section{Results}

The average PDAQ score was $37.72(S D=17.06)$. The range of PDAQ scores was 19 - 95. Male students had significantly higher PDAQ scores $(\mathrm{M}=43.68, \mathrm{SD}=19.67)$ compared to female students $(M=35.84, S D=$ $15.74 ; t(250)=2.81, p=.00)$. No significant differences in PDAQ score were found by class year, $F(3,250)$ $=.88, p=.46$. Age was significantly positively associated with the PDAQ scale $(r=.15, p<.05)$. The average number of drinks per week consumed was $6.96(S D=7.84)$ with a range of $0-45$. Participants reported on average using marijuana 2.82 times a month $(S D=6.28)$ with a range of 0 - 30 times. The average number of times a month that participants reported using prescription pills (not prescribed to them by a health care provider) per month was $.84(S D=5.49)$ with a range of 0 - 60 times. Participants reported using illicit drugs (not including marijuana) .23 times a month $(S D=1.27)$ with a range of $0-15$.

\subsection{Principal Components Analysis}

Items that did not correlate well with other items were dropped from the scale and not included in the factor analysis. Seven items met this criterion and were dropped from the analysis. The Kaiser-Meyer-Olkin measure verified the sampling adequacy for the analysis, $\mathrm{KMO}=.94$, and suggested that the correlation patterns were 
compact and a factor analysis should produce distinct and reliable factors (Field, 2013). Bartlett's test of sphericity $X^{2}(171)=3259.06, p<.00$, indicated that correlations between items were sufficiently large for a Principal Components Analysis (PCA). A PCA was conducted on the 19 items with oblique rotation (direct oblimin) and initially resulted in two components with an eigenvalue greater than one. The Scree plot indicated that these two components should be retained. The two-factor solution accounted for $58.28 \%$ of the variance. Eleven items loaded on the first factor (recreational) and eight items loaded on the second (achievement-oriented; see Table 1 for component loadings).

\subsection{Reliability}

Internal consistency for the overall PDAQ scale and two PDAQ subscales was evaluated by computing Cronbach alpha for the sample. Cronbach's alpha for the overall scale was .94, factor one was .92 and factor two was .89 .

\subsection{Convergent Validity}

As there are currently no other scales that measure attitudes towards prescription drug use, the CAPS-R and self-reported substance use were used to establish convergent validity. The 19-item PDAQ scale was compared to a measure of substance abuse problems among college students, the College Alcohol Problems Scale Revised (CAPS-R), as well as self-reported substance use. The CAPS-R has been shown to be a valid and reliable measure of social and personal problems associated with drinking in college students (Maddock, 2001). The correlations between the subscales of the CAPS-R, total score for the CAPS-R, the PDAQ total score and scores on the two factors are listed in Table 2. Results suggest a significant positive relationship between the PDAQ and the

Table 1. Prescription drug attitudes questionnaire factor loadings.

\begin{tabular}{|c|c|}
\hline ITEMS & LOADINGS \\
\hline \multicolumn{2}{|l|}{ Factor 1-Recreational } \\
\hline It is acceptable for an athlete to borrow someone's prescription medication in order to enhance their athletic performance & .82 \\
\hline It is ok for an individual to take medication that is not prescribed to them in order to decrease appetite and lose weight & .79 \\
\hline There are certain situations where it is ok to take someone else's prescribed medication. & .77 \\
\hline There isn't anything wrong with someone taking a medication not prescribed to them in order to enhance sexual activity. & .75 \\
\hline If a person is in physical pain from an injury, taking someone else's medication is okay in that situation & .70 \\
\hline If a prescription drug makes a person have more fun at a party it’s worth taking it. & .60 \\
\hline As long as it makes you feel better and not worse, it is fine to take prescription drugs while drinking. & .59 \\
\hline Using prescribed medications just to stay awake at a party is okay. & .59 \\
\hline $\begin{array}{l}\text { If an individual feels awkward in social situations, it is okay for them sometimes to take a medication that is } \\
\text { not prescribed to them if it makes them feel better. }\end{array}$ & .59 \\
\hline Using other people’s prescription medications in order feel less stressed is fine in a pinch. & .57 \\
\hline \multirow{2}{*}{\multicolumn{2}{|c|}{$\begin{array}{l}\text { It's fine if a person takes a friend's prescription drug if it helps him or her to become more sociable } \\
\text { and enjoy their surroundings. }\end{array}$}} \\
\hline & \\
\hline People shouldn't take medication not prescribed to them in order to finish their school work faster. & .81 \\
\hline Taking medication that is not prescribed to you should be illegal. & .70 \\
\hline An individual should only take medication that is prescribed to them by a medical professional. & 69 \\
\hline $\begin{array}{l}\text { It is okay for an individual to take medication that is not prescribed to them in order to stay up later } \\
\text { and get more accomplished. }\end{array}$ & .60 \\
\hline I would try a medication that is not prescribed to me if it was given to me for free. & .54 \\
\hline $\begin{array}{l}\text { If an individual is trying to improve their grades, it is okay for them to take medication that is } \\
\text { not prescribed to them just to help with studying. }\end{array}$ & .53 \\
\hline It is alright for someone to take a friend's medication if it helps them concentrate and think more clearly during an exam. & .52 \\
\hline
\end{tabular}


Table 2. Correlations among PDAQ Scale and Validity Measures.

\begin{tabular}{|c|c|c|c|c|c|c|c|c|c|c|c|}
\hline & & 1 & 2 & 3 & 4 & 5 & 6 & 7 & 8 & 9 & 10 \\
\hline 1. & PDAQ- Total & - & & & & & & & & & \\
\hline 2. & Recreational & $.95^{* *}$ & - & & & & & & & & \\
\hline 3. & Achievement & $.95^{* *}$ & $.81^{* *}$ & - & & & & & & & \\
\hline 4. & CAPS- Total & $.37^{* *}$ & $.32^{* *}$ & $.38^{* *}$ & - & & & & & & \\
\hline 5. & CAPS-Social & $.48^{* *}$ & $.44^{* * *}$ & $.48^{* *}$ & $.79^{* *}$ & - & & & & & \\
\hline 6. & CAPS- Personal & $.16^{*}$ & .12 & $.18^{* *}$ & $.86^{* *}$ & $.36^{* *}$ & - & & & & \\
\hline 7. & Alcohol Use & $.44^{* * *}$ & $.40^{* *}$ & $.44^{* * *}$ & $.39^{* *}$ & $.57^{* *}$ & .11 & - & & & \\
\hline 8. & Marijuana Use & $.32^{* *}$ & $.28^{* *}$ & $.28^{* *}$ & $.31^{* *}$ & $.43^{* *}$ & .11 & $.32^{* *}$ & - & & \\
\hline 9. & $\begin{array}{l}\text { Prescription } \\
\text { Drug use }\end{array}$ & .04 & .03 & .05 & .07 & .02 & .08 & .02 & .00 & - & \\
\hline 10. & Illicit Drug Use & $.36^{* *}$ & $.35^{* *}$ & $.34^{* *}$ & $.24^{* *}$ & $.40^{* *}$ & .03 & $.37^{* *}$ & $.19^{* *}$ & $.15^{*}$ & - \\
\hline
\end{tabular}

Prescription Drug Attitudes Questionnaire (PDAQ), College Alcohol Problems Scale (CAPS), ${ }^{*}<.05,{ }^{* *}<.01$.

CAPS total score as well as the two subscales (social and personal problems).

The total PDAQ score was significantly positively correlated with number of alcoholic drinks consumed per week, marijuana use per month, and other illicit drug use. Both of the PDAQ factors also positively correlated with these variables. No significant correlation was found between use of prescription pills per month and the PDAQ scale and two factors.

Given the low number of participants in our sample who reported using prescription drugs for nonmedical purposes in the last month $(\mathrm{N}=29)$, we examined differences on the PDAQ by those who misused those drugs compared to those who did not. Those who did report using prescription pills not prescribed to them in the last month had more positive attitudes towards prescription pills $(M=57.21, S D=19.98)$ compared to those who did not report such use $(M=35.17, S D=14.90, t(249)=-5.73, p<.00)$. Prescription drug misusers also had higher scores on the achievement factor $(M=28.03, S D=9.7)$ compared to those who did not misuse prescription drugs in the last month $(M=16.13, S D=7.43 ; t(249)=-6.36, p=.00)$. Recreational factor scores were also higher among misusers $(M=29.4, S D=11.26)$ compared to nonusers of prescription drugs $(M=19.03, S D$ : 8.41; $\mathrm{t}(250)=-4.86, p=.00)$.

\section{Discussion}

The purpose of the present study was to develop and validate a scale that would measure college students' attitudes about prescription drugs. Our results provide initial support for the psychometric properties of the PDAQ and suggest that it could be a valuable tool for use in college settings. Two factors emerged from the analyses of the PDAQ: recreational and achievement-oriented attitudes towards the use of prescription drugs. Each of these two factors correlated with the PDAQ total score and the PDAQ instrument was positively related to alcohol problems as measured by the CAPS-R, alcohol, marijuana and other illicit drug use. The PDAQ total scale and two factors demonstrated good internal consistency.

Interestingly, we found no correlation between the PDAQ and prescription drug use in our sample. This may be related to our low levels of reported prescription drug misuse (average was less than once a month) and relatively high sample of first year college students. The reported low-rates of use may be a function of actual use, this particular sample (small liberal arts college in northeast), and/or bias in self-reporting. We found a correlation between more positive attitudes towards these drugs and age, which might suggest that older students (and upper classmen) may be more prone to using these drugs. It may be the case that substances such as alcohol and marijuana are more frequently used and accessible during a student's first year at college and as students expand their networks on campus; prescription drugs become more readily available. This may explain the positive association between alcohol use, illicit drug use and PDAQ scores. Prescription drug misusers having significantly more positive attitudes towards prescription drug use (compared to nonusers) suggests that if there was more variability in prescription drug misusers in our sample, we may have found a relationship between the PDAQ and prescription drug misuse. Researchers should explore this scale with a range of participants from different backgrounds and classes. 
This research lays the foundation for further investigation into how adolescents and young adults view prescription drugs and the impact this may have on subsequent substance use. Attitudes have vast effects on behavior (Azjen, 1985); therefore we should not dismiss the impact that beliefs about prescription drugs have on actual use. Substance use disorders affect both mental and physical health and have a tremendous financial cost to society (Kuehn, 2012). By understanding how different types of drugs are viewed and how this in turn may impact their use, we can work towards changing attitudes of individuals in high schools or on college campuses where rates of abuse are high. Campaigns that target changing faulty attitudes and providing information about the effects from misuse of prescription drugs may help to lower rates of misuse among these groups, but first we must understand how these drugs are viewed. The PDAQ scale is the first step towards doing this.

This study supports the initiative to do more to protect young adults and adolescents from the devastating effects of prescription misuse. Rosenfield and colleagues (2011) called upon University administrators and personnel to work towards understanding and addressing the causes of prescription drug abuse (especially stimulants). As many students use prescription drugs such as stimulants to help boost academic performance, more work is needed in debunking the myths that are ubiquitous on college campuses about the usefulness of such drugs. The authors give several suggestions for University personnel to help conquer this growing epidemic on college campuses including educating students about the consequences of prescription misuse, helping students to develop proper study habits, and holding students responsible for stimulant misuse (i.e., as they would underage drinking) (Rosenfield, Hebert, Stanbrook, Flegel, \& MacDonald, 2011).

There are limitations to this research that should be mentioned. As mentioned earlier, over half the sample consisted of freshmen. More research examining this scale and prescription drug misuse is needed for the upperclassman population. Our detected rates of prescription drug use were low compared to other research (Weyandt et al., 2013). Replicating this study in a sample with higher rates of use and with more diversity would be beneficial. Given that participants were from a small liberal arts college in the northeast, generalizability to other populations is limited and should be explored in future research. Also, data on the types of prescription drugs used in this sample was not collected. Given that commonly misused prescription drugs have different effects on the body, it could be important to see how attitudes varied by drug type.

\section{Conclusion}

The development of the PDAQ scale is the first step towards reliable and valid measurement of attitudes towards prescription drugs. It is the first scale of its kind to be validated in a college population. Having a psychometrically sound assessment tool is essential for both researchers and clinicians who are interested in studying individuals who misuse prescription drugs.

\section{References}

Arria, A. M., Caldeira, K. M., Vincent, K. B., O’Grady, K. E., \& Wish, E. D. (2008). Perceived Harmfulness Predicts Nonmedical Use of Prescription Drugs among College Students: Interactions with Sensation-Seeking [Research Support, N.I.H., Extramural]. Prevention Science, 9, 191-201. http://dx.doi.org/10.1007/s11121-008-0095-8

Azjen, I. (1985). From Intention to Actions: A Theory of Planned Behavior. In J. Kuhl, \& J. Beckman (Eds.), Action-Control: From Cognition to Behavior (pp. 11-39). Heidelberg: Springer.

Biegler, P., \& Vargas, P. (2013). Ban the Sunset? Nonpropositional Content and Regulation of Pharmaceutical Advertising. The American Journal of Bioethics, 13, 3-13. http://dx.doi.org/10.1080/15265161.2013.776127

CDC (2011). Overdoses of Prescription Opioid Pain Relievers-United States, 1999-2008. MMWR.

Drugfree.org, T. P. A., \& Foundation, M. (2013). PATS Key Findings: 2012 Partnership Attitude Tracking Study. http://ww1.prweb.com/prfiles/2013/04/24/10667804/PATS-2012-KEY-FINDINGS.pdf

Dussault, C. L., \& Weyandt, L. L. (2013). An Examination of Prescription Stimulant Misuse and Psychological Variables among Sorority and Fraternity College Populations. Journal of Attention Disorders, 17, 87-97.

http://dx.doi.org/10.1177/1087054711428740

Field, A. (2013). Discovering Statistics Using IBM SPSS Statistics (4th ed.). SAGE.

Gomes, J., Song, T., Godwin, L., \& Toriello, P. J. (2011). Prescription Stimulant Abuse on University Campuses. Journal of Human Behavior in the Social Environment, 21, 822-833. http://dx.doi.org/10.1080/10911359.2011.615680

Jardin, B., Looby, A., \& Earleywine, M. (2011). Characteristics of College Students with Attention-Deficit Hyperactivity Disorder Symptoms Who Misuse Their Medications. Journal of American College Health, 59, 373-377. 
Kuehn, B. M. (2012). WHO Documents Worldwide Need for Better Drug Abuse Treatment—And Access to It. Journal of the American Medical Association, 308, 442-443. http://dx.doi.org/10.1001/jama.2012.8882

Maddock, J. E., Laforge, R. G., Rossi, J. S., \& O’Hare, T. (2001). The College Alcohol Problems Scale. Addictive Behaviors, 26, 385-398. http://dx.doi.org/10.1016/S0306-4603(00)00116-7

McCabe, S. E., \& Teter, C. J. (2007). Drug Use Related Problems among Nonmedical Users of Prescription Stimulants: A Web-Based Survey of College Students from a Midwestern University [Research Support, N.I.H., Extramural]. Drug and Alcohol Dependence, 91, 69-76. http://dx.doi.org/10.1016/j.drugalcdep.2007.05.010

McCabe, S. E., Knight, J. R., Teter, C. J., \& Wechsler, H. (2005). Non-Medical Use of Prescription Stimulants among US College Students: Prevalence and Correlates from a National Survey [Research Support, Non-U.S. Gov't Research Support, U.S. Gov’t, P.H.S.]. Addiction, 100, 96-106. http://dx.doi.org/10.1111/j.1360-0443.2005.00944.x

McCabe, S. E., Teter, C. J., \& Boyd, C. J. (2005). Illicit Use of Prescription Pain Medication among College Students [Comparative Study Research Support, U.S. Gov’t, P.H.S.]. Drug and Alcohol Dependence, 77, 37-47.

http://dx.doi.org/10.1016/j.drugalcdep.2004.07.005

National Institute on Drug Abuse (2011). Topics in Brief: Prescription Drug Abuse. http://www.drugabuse.gov/publications/topics-in-brief/prescription-drug-abuse

O’Hare, T. (1998). Replicating the College Alcohol Problem Scale (CAPS) with College First Offenders. Journal of Alcohol and Drug Education, 43, 75-82.

O’Hare, T., \& Sherrer, M. V. (1998). Drinking Problems, Alcohol Expectancies and Drinking Contexts in College First Offenders. Journal of Alcohol and Drug Education, 43, 31-45.

Partridge, B., Bell, S., Lucke, J., \& Hall, W. (2013). Australian University Students’ Attitudes towards the Use of Prescription Stimulants as Cognitive Enhancers: Perceived Patterns of Use, Efficacy and Safety [Research Support, Non-U.S. Gov't]. Drug and Alcohol Review, 32, 295-302. http://dx.doi.org/10.1111/dar.12005

Rosenfield, D., Hebert, P. C., Stanbrook, M. B., Flegel, K., \& MacDonald, N. E. (2011). Time to Address Stimulant Abuse on Our Campuses [Editorial]. Candian Medical Association Journal, 183, 1345. http://dx.doi.org/10.1503/cmaj.111149

Sepulveda, D. R., Thomas, L. M., McCabe, S. E., Cranford, J. A., Boyd, C. J., \& Teter, C. J. (2011). Misuse of Prescribed Stimulant Medication for ADHD and Associated Patterns of Substance Use: Preliminary Analysis among College Students [Research Support, N.I.H., Extramural]. Journal of Pharmacy Practice, 24, 551-560.

http://dx.doi.org/10.1177/0897190011426558

Stone, A. M., \& Merlo, L. J. (2012). Psychiatric Medication-Seeking Beliefs and Behaviors among College Students [Research Support, N.I.H., Extramural Research Support, Non-U.S. Gov't]. American Journal of Drug and Alcohol Abuse, 38, 314-321. http://dx.doi.org/10.3109/00952990.2011.643992

Substance Abuse and Mental Health Services Administration (2013). Emergency Department Visits Involving Attention Deficit/Hyperactivity Disorder Stimulant Medications. http://www.samhsa.gov/daa/2k13/DAWN073/sr073-ADD-ADHD-medications.htm

Talbott, L. L., Umstattd, M., Usdan, S. L., Martin, R. J., \& Geiger, B. F. (2009). Validation of the College Alcohol Problem Scale-Revised for Use with Non-Adjudicated First Year Students. Addictive Behaviors, 34, 471-473. http://dx.doi.org/10.1016/j.addbeh.2008.12.005

West, S., \& Graham, C. W. (2001). Assessing the Validity of the College Alcohol Problem Scale with African American Undegraduates: Results of a Preliminary Investigation. Journal of Alcohol and Drug Education, 46, 4-17.

Weyandt, L. L., Janusis, G., Wilson, K. G., Verdi, G., Paquin, G., Lopes, J., Varejao, M., \& Dussault, C. (2009). Nonmedical Prescription Stimulant Use among a Sample of College Students: Relationship with Psychological Variables. Journal of Attention Disorders, 13, 284-296. http://dx.doi.org/10.1177/1087054709342212

Weyandt, L. L., Marraccini, M. E., Gudmundsdottir, B. G., Zavras, B. M., Turcotte, K. D., Munro, B. A., \& Amoroso, A. J. (2013). Misuse of Prescription Stimulants among College Students: A Review of the Literature and Implications for Morphological and Cognitive Effects on Brain Functioning. Experimental and Clinical Psychopharmacology, 21, 385-407. http://dx.doi.org/10.1037/a0034013

Zullig, K. J., \& Divin, A. L. (2012). The Association between Non-Medical Prescription Drug Use, Depressive Symptoms, and Suicidality among College Students [Multicenter Study]. Addictive Behaviors, 37, 890-899. http://dx.doi.org/10.1016/j.addbeh.2012.02.008 
Scientific Research Publishing (SCIRP) is one of the largest Open Access journal publishers. It is currently publishing more than 200 open access, online, peer-reviewed journals covering a wide range of academic disciplines. SCIRP serves the worldwide academic communities and contributes to the progress and application of science with its publication.

Other selected journals from SCIRP are listed as below. Submit your manuscript to us via either submit@scirp.org or Online Submission Portal.
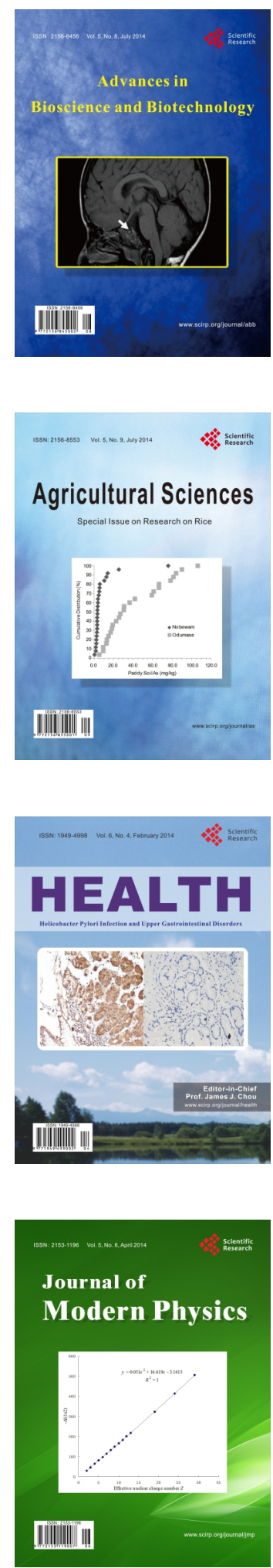
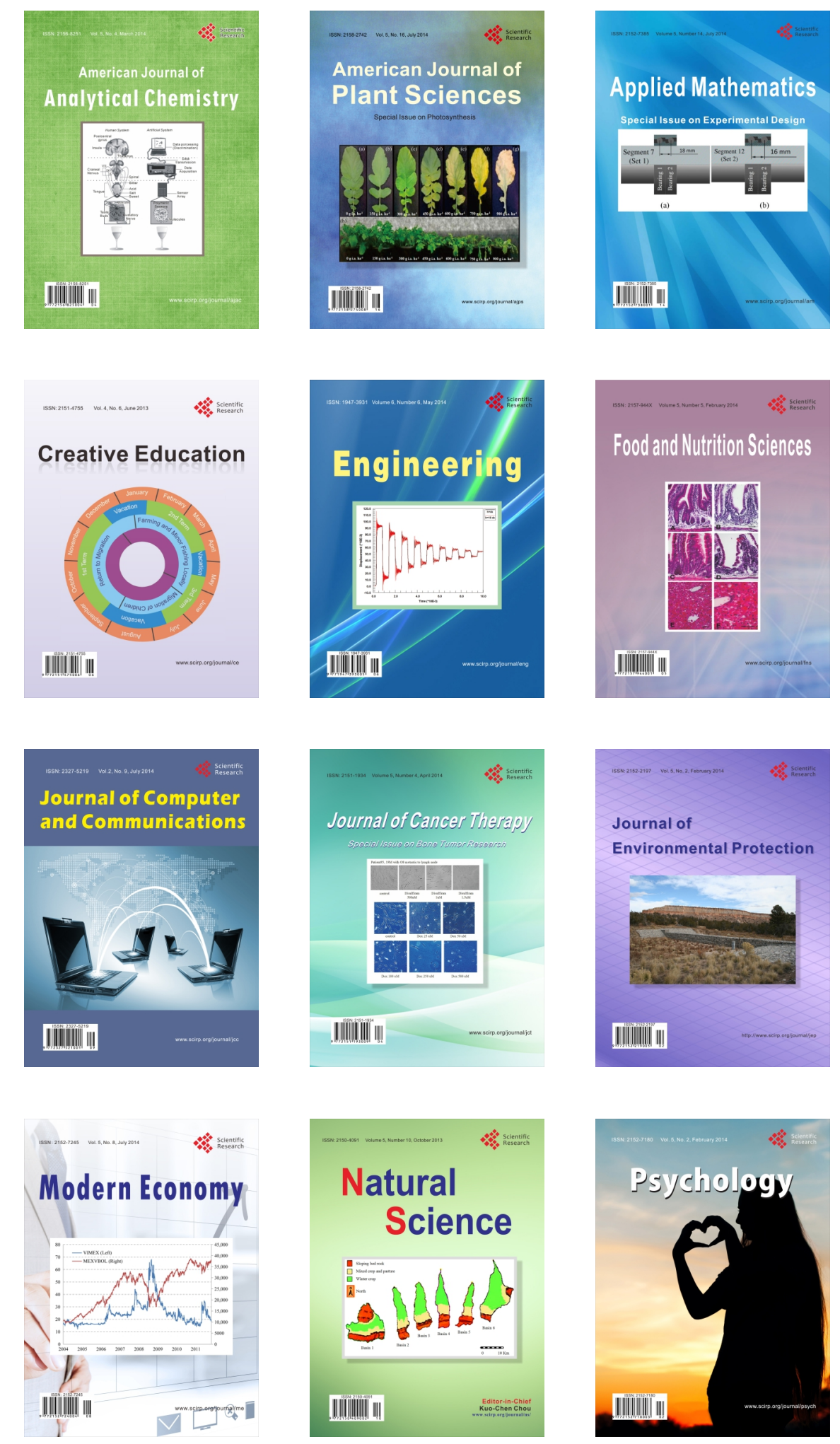